УДК 316.4

$10.17213 / 2075-2067-2021-3-26-31$

\title{
СПЕЦИФИКА РАЗВИТИЯ ПРОЕКТНОЙ КУЛЬТУРЫ СТУДЕНЧЕСКОЙ МОЛОДЕЖИ ТЕХНИЧЕСКОГО ВУЗА
}

\author{
(C) 2021 г. Т. И. Загороднюк*, Е. В. Загороднюк** \\ "Южнный федеральный университет, г. Ростов-на-Дону, Россия \\ ** Южно-Российский государственный политехнический университет (НПИ) \\ имени М. И. Платова, г. Новочеркасск, Россия
}

Цель исследования. $B$ статье рассматривается отношение студентов 1-2 курсов ЮРГПУ (НПИ) к проектному обучению и проектной культуре. Определены компетенции, недостающие студентам для успешной реализачии проектного обучения, даны рекомендации преподавателям по реализации проектного обучения, исходя из представленных ответов.

Методы исследования. Для оценки сформированности проектной компетенции студентов использован опросник, составленный на базе шкаль Ликерта.

Результаты исследования. Ответы студентов оценены с применением корреляционного и дисперсионного анализа.

Ключевые слова: Шкала Ликерта; проектное обучение; командные компетенции; проектные компетенции; Шкала Чеддока.

\section{THE SPECIFICS OF THE DEVELOPMENT OF THE PROJECT CULTURE OF THE STUDENTS OF THE TECHNICAL UNIVERSITY}

\author{
(C) 2021 T. I. Zagorodnyuk , E. V. Zagorodnyuk ${ }^{* *}$ \\ "Southern Federal University, Rostov-on-Don, Russia \\ **Platov South Russian State Polytechnic University (NPI), Novocherkassk, Russia
}

The purpose of the study. The article examines the attitude of students of the 1st-2nd courses of the SRSPU (NPI) to project training and project culture. The competencies that students lack for the successful implementation of project-based learning are identified, and recommendations are given to teachers on the implementation of project-based learning, based on the answers provided.

Research methods. To assess the formation of students ' project competence, a questionnaire based on the Likert scale was used.

The results of the study. The students ' responses were evaluated using correlation and variance analysis.

Key words: Likert Scale; project-based learning; team competence; project competence; Cheddock Scale. 
Введение. Федеральные государственные образовательные стандарты основного общего образования включают требования подготовки выпускников 11 классов, потому бакалавры 1-2 курса должны иметь определенный уровень сформированности проектной компетенции. Однако, как показывает практика, степень подготовки студентов к работе с образовательными проектами разнится, следовательно, для эффективной работы с образовательными проектами необходимо знать, насколько развита проектная компетенция студентов 1-2 курса, чтобы повысить качество проектной деятельности обучающихся и эффективно выстроить взаимодействие «студент - преподаватель» при реализации образовательных проектов.

В реальной жизни большинство реализуемых проектов требует также работы в команде. Дмитрий Песков отмечал, что нужно осуществлять подготовку не дипломированных индивидов [4], а команд как будущий тренд развития высшего образования, поэтому в исследования включены вопросы, изучающие отношение студентов к командным проектам.

Проведенное исследование должно показать вектор развития проектного обучения в ЮРГПУ (НПИ) имени М.И. Платова.

Гипотеза исследования. В рамках исследования выдвигалась следующая гипотеза: студенты ЮРГПУ заинтересованы в проектном обучении и могут получить поддержку в школе и вузе, однако им требуется развитие компетенций, связанных с проектной деятельностью и командной работой.

Из этой гипотезы можно выявить ряд подгипотез:

1) студенты мотивированы на участие в реализации командных проектов;

2) студенты могут получить достаточную поддержку в школе для реализации проектной деятельности;

3) студенты могут получить достаточную поддержку в вузе для реализации проектной деятельности;

4) студентам требуется развитие компетенций, связанных с проектной деятельностью;

5) студентам требуется развитие компетенций, связанных с командной работой.
В соответствии в подгипотезами были сформулированы вопросы опросника, основанные на шкале Ликерта.

Методика исследования. Построение шкалы Ликерта используется для измерения социальной установки респондента.

Под установкой понимают индивидуальное ценностное отношение к объекту, которое выражается в психологической готовности к положительной или отрицательной реакции на данный объект [3].

Шкала Ликерта представляет собой суждения или вопросы, которые испытуемому нужно оценить, исходя из своего личного представления. Используется 5 градаций:

1) совершенно согласен;

2) скорее согласен, чем нет;

3) затрудняюсь ответить;

4) скорее не согласен, чем согласен;

5) совершенно не согласен.

Далее для удобства математической обработки каждому ответу присваивается числовое значение от 1 до 5. Для прямого к гипотезе предположения: «совершенно согласен» - 5; «скорее согласен, чем нет» - 4; «затрудняюсь ответить» - 3 ; «скорее не согласен, чем согласен» - 2 ; «совершенно не согласен» - 1. Для обратного предположения: «совершенно согласен» - 1 ; «скорее согласен, чем нет» - 2; «затрудняюсь ответить» - 3; «скорее не согласен, чем согласен» - 4; «совершенно не согласен» - 5 .

В основу исследования был положен дисперсионный анализ и корреляционный анализ на основе метода ранговой корреляции Спирмена.

Коэффициент ранговой корреляции Спирмена - это непараметрический критерий, который используется с целью статистического изучения связи между явлениями. В этом случае определяется фактическая степень зависимости между двумя количественными рядами изучаемых признаков и дается оценка тесноты установленной связи с помощью количественно выраженного коэффициента [5].

Для интерпретации коэффициента ранговой корреляции применялась шкала Чеддока [2].

Дисперсионный анализ. Дисперсия случайной величины - это один из основ- 
Таблица 1

Значение корреляции и коэффициент Спирмена

\begin{tabular}{|c|c|}
\hline Значение коэффициента корреляции & Сила связи \\
\hline Менее 0,3 & Слабая \\
\hline От 0,3 до 0,5 & Умеренная \\
\hline От 0,5 до 0,7 & Заметная \\
\hline От 0,7 до 0,9 & Высокая \\
\hline Более 0,9 & Весьма высокая \\
\hline
\end{tabular}

ных показателей в статистике. Он отражает меру разброса данных вокруг средней арифметической [1]. Данный анализ был завершен на оценке значений дисперсий, которая позволит определить разброс мнений вокруг среднего варианта ответа, что позволит определить степень слаженности ответов на поставленные вопросы.

Результаты исследования. Первая выдвинутая подгипотеза «Студенты мотивированы на участие в реализации командных проектов» нашла свое подтверждение, поскольку среднее значение ответов, полученных по пунктам: «Обучение основам создания проектов в школе полезно для школьников» - 4,06, что примерно соответствует ответам «совершенно согласен» и «скорее согласен, чем нет»; «Создание проектов во время обучения в вузе будет полезно для профессионального развития» - 4,27, «Мне интересно участвовать в реализации образовательных и реальных проектов» - 3,8 (что попадает в промежуток между «скорее согласен, чем нет» и «затрудняюсь ответить»), притом дисперсия по данным пунктам составляет $1,3,1,07,1,7$ соответственно, что демонстрирует минимальный разброс ответов студентов в данном исследовании. Следовательно, студенты 1-2 курсов ЮРГПУ мотивированы на проектное обучение, хотя уровень заинтересованности в нем ниже, чем уровень понимания полезности проектного обучения.

Вторая подгипотеза «Студенты могут получить достаточную поддержку в школе для реализации проектной деятельности» не нашла своего подтверждения. Средний балл по пункту «В рамках школьного обучения разбираются основы работы в команде, налаживания диалога, достаточные для реализации проекта» - 2,65 при этом дисперсия составила 2,4, что демонстрирует максимальный разброс мнений респондентов и разность уровней проектной подготовки, с которой студенты приходят в вуз.

Третья гипотеза «Студенты могут получить достаточно поддержки в вузе для реализации проектной деятельности» подтверждена частично по пункту «Университетские преподаватели могут оказать помощь по всем вопросам, касающимся реализации образовательных проектов» - средний балл 3,7 , что ближе к ответу «скорее согласен, чем нет», дисперсия - 1,2. По пункту «В рамках университетской программы разбираются основы работы в команде налаживания диалога, достаточные для реализации проекта» - средний балл 3,1 , дисперсия 1,6 . По пункту «В рамках университетской программы дается достаточно знаний для реализации индивидуальных и командных проектов» - оценка 3,08, дисперсия - 1,5. Также корреляция суммарной величины шкалы Ликерта (общей гипотезы, нашедшей частичное подтверждение) и мнение студентов относительно позиции «В рамках университетской программы дается достаточно знаний для реализации индивидуальных и командных проектов» составила 0,731, следовательно, имеется высокой степени силы связь отношения студентов к проектному обучению в целом с уровнем проектного обучения в университете.

Кроме того, заметный уровень корреляции с выдвинутой гипотезой составляют такие критерии, как «Университетские преподаватели могут оказать помощь по всем 
вопросам, касающимся реализации образовательных проектов» (уровень корреляции $0,54)$ и «В рамках университетской программы разбираются основы работы в команде налаживания диалога, достаточные для реализации проекта» (корреляция 0,49).

Гипотеза о потребности студентов в развитии компетенций, связанных с проектной деятельностью, нашла свое подтверждение. «Планирование проектов требует специальных знаний» - балл 3,5, дисперсия - 1,3.

Гипотеза о потребности развития компетенций, связанных с работой в команде. Поскольку средний балл обратной гипотезы, составленный по правилу вычисления балла обратной гипотезы, составил 2,5, что находится в промежутке между «скорее согласен, чем нет» и «затрудняюсь ответить», дисперсий 1,4, и, кроме того, уровень корреляции обратной гипотезы, рассчитанный исходя из правил оценки обратной гипотезы и основной гипотезы, составил 0,25, следовательно, по мнению студентов, развитие командных компетенций не влияет на их отношение к проектному обучению. Также студенты не определились относительно преимуществ командных проектов над индивидуальными. Средний балл отношения к суждению «Реализация командных проектов в период обучения полезнее, чем реализация индивидуальных проектов» составил 3,1 , дисперсия - 1,5.

Выводы. Как показало исследование, студенты мотивированы для участия в проектной деятельности, однако их проектная компетенция недостаточно сформирована. При этом, исходя из показателей дисперсии ответов, в рамках основного общего образования студенты получают различный уровень проектных компетенций: от отсутствия представления о проектных компетенциях (42,9\% опрошенных не участвовали в проектной деятельности) до участия в конкурсах проектов (38,8 \% опрошенных), что предполагает дифференцированный подход к реализации проектного образования. Поэтому до реализации образовательной проектной деятельности, преподавателям необходимо:

- проводить диагностику уровня сформированности проектной компетенции с целью организации дополнительных консуль- таций (лекций) по основам проектной деятельности для студентов, не участвовавших в проектном обучении ранее,

- предоставить более широкий спектр заданий для студентов, участвовавших ранее в проектной деятельности, поскольку студенты не могут точно определить свое отношение к реализации проектного обучения в рамках вуза.

При этом студенты доверяют компетенции преподавателей ЮРГПУ в организации проектной деятельности и считают, что могут рассчитывать на их поддержку в реализации образовательных проектов.

Опрошенные не соотносят развитие проектной компетенции и компетенций, связанных с работой в команде, что требует дополнительных исследований форм развития командных компетенций в рамках ЮРГПУ и реализации командных проектов.

\section{Литература}

1. Дисперсия, среднеквадратичное (стандартное) отклонение, коэффициент вариации в Excel [Электронный ресурс]. — Режим доступа: https://statanaliz.info/statistica/opisaniedannyx/dispersiya-standartnoe-otkloneniekoeffitsient-variatsii/.

2. Mapanoв Д. Критерий Спирмена [Электронный ресурс]. — Режим доступа: https:// medstatistic.ru/methods/methods9.html.

3. Одномерное шкалирование. Шкала Лайкерта [Электронный ресурс]. — Режим доступа: https://ppt-online.org/281291.

4. Песков Д.Н. Высшая школа в эпоху 20-х [Электронный ресурс]. — Режим доступа: https:/www.youtube.com/watch?v=nOAThNN5VM.

5. Прохорова Н. Ю., Смирнова А. С. Применение коэффициента корреляции Спирмена в медико-биологическом эксперименте // Российская наука в современном мире. Сборник статей X международной научнопрактической конференции. - М.: «Научно-издательский центр «Актуальность. РФ», 2017. - С. 117-118.

\section{References}

1. Dispersija, srednekvadratichnoe (standartnoe) otklonenie, kojefficient variacii v Excel 
[Variance, standard deviation, coefficient of variation in Excel] [Jelektronnyj resurs]. — URL: https://statanaliz.info/statistica/opisanie-dannyx/ dispersiya-standartnoe-otklonenie-koeffitsientvariatsii/.

2. Marapov D. Kriterij Spirmena [Spearman's criterion] [Jelektronnyj resurs]. — URL: https://medstatistic.ru/methods/methods9.html.

3. Odnomernoe shkalirovanie. Shkala Lajkerta [One-dimensional scaling. The Likert scale] [Jelektronnyj resurs]. — URL: https://ppt-online.org/281291.

4. Peskov D.N. Vysshaja shkola $\mathrm{v}$ jepohu 20-h [Higher school in the era of the 20s] [Jele- ktronnyj resurs]. — URL: https://www.youtube. $\mathrm{com} /$ watch? $\mathrm{v}=$ nOATh-NN5VM.

5. Prohorova N. Ju., Smirnova A. S. Primenenie kojefficienta korreljacii Spirmena v medikobiologicheskom jeksperimente [Application of the Spearman correlation coefficient in a medical-biological experiment] // Rossijskaja nauka v sovremennom mire. Sbornik statej $\mathrm{X}$ mezhdunarodnoj nauchno-prakticheskoj konferencii [Russian science in the modern world. Collection of articles of the X international scientific and practical conference]. - Moscow: «Nauchno-izdatel'skij centr «Aktual'nost'. RF», 2017. - Pp. 117-118.

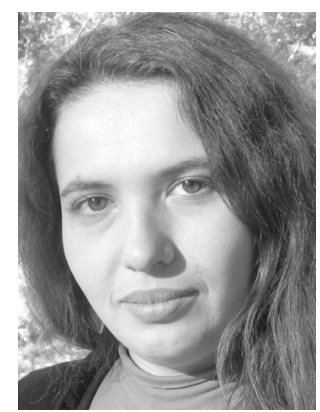

Загороднюк Татьяна Игоревна - аспирантка второго года обучения Академии психологии и педагогики Южного Федерального университета.

Zagorodnyuk Tatyana Igorevna - a 2nd-year Postgraduate Student of the Academy of Psychology and Pedagogy, Southern Federal University.

344114, г. Ростов-на-Дону, ул. Беляева, 11, кв. 2

11 Belyaeva st., app. 2, 344114, Rostov-on-Don, Russia

E-mail: ktu1989@mail.ru 


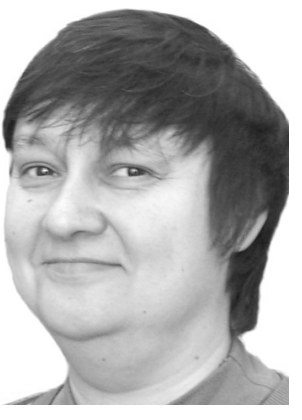

Загороднюк Елена Вячеславовна — кандидат технических наук, доцент кафедры «Социальные и гуманитарные науки» Южно-Российского государственного политехнического университета (НПИ) имени М.И. Платова.

Zagorodnyuk Elena Vyacheslavovna - Candidate of Engineering Sciences, Associate Professor of the Department of «Social and Humanitarian Sciences», Platov South Russian State Polytechnic University (NPI).

346411, г. Новочеркасск, ул. Народная, 62/2, кв. 57

62/2 Narodnaya st., app. 57, 346411, Novocherkassk, Russia

E-mail: zagor-e.v@yandex.ru 